\title{
The human factor in alpine skiing and snowboarding accidents
}

\author{
Iñigo Soteras Martínez', Alberto Ayora Hirsch², Bernat Escoda Alegret' ${ }^{3}$, Guillermo Sanz Junoy ${ }^{4}$, Enric Subirats Bayego ${ }^{1}$ \\ ${ }^{1}$ Facultad de Medicina-Universidad de Girona. ${ }^{2}$ Comité de Seguridad FEDME. ${ }^{3}$ Centre Mèdic Pas de la Casa-Grau Roig. ${ }^{4}$ Universidad Rey Juan Carlos de Madrid.
}

doi: 10.18176/archmeddeporte.00031

Received: 01/05/2020

Accepted: 09/01/202

Key words:

Skiing injuries. Snow sports.

Human factors.

\section{Summary}

Introduction: Hundreds of millions of people practice winter sports worldwide. Alpine skiing and snowboarding are associated with a possible risk of injury. There are at least three important factors that can affect safety in wilderness activities (environmental factors, technical factors and human factors). Awareness of human factors would allow us to reduce the risk in winter sports. Material and method: The objective of this study is to find out, through a self-explanatory cross-sectional personal survey, what and how human factors are involved in alpine skiing and snowboarding accidents.

Results: 219 surveys were carried out of a total of 3,911 patients attended at the different health care points. The highest percentage of respondents related their accident to distraction or complacency, both in $72.2 \%$ of the respondents. Other factors that were pointed out by more than $50 \%$ were; lack of knowledge (60.4\%), lack of following the norms (58.5\%), fatigue (57.5\%), lack of situational awareness (57\%) and stress with (53.8\% of the respondents).

Conclusions: By identifying these most frequent human factors during downhill skiing and snowboarding, actions can be taken to prevent or contain human error.

\section{El factor humano en los accidentes de esquí alpino y snowboard}

\section{Resumen}

Introducción: Cientos de millones de personas practican deportes de invierno en todo el mundo. A la práctica de esquí alpino y snowboard se le asocia un posible riesgo de lesión. Existen al menos tres factores importantes que pueden afectar a la seguridad en las actividades del medio natural (factores ambientales, factores técnicos y factores humanos). El conocimiento de los principales factores humanos nos permitiría reducir el riesgo en los deportes de invierno.

Material y método: El objetivo de este estudio es el conocer, por medio de una encuesta personal auto-cumplimentada explicativa transversal, cómo y qué factores humanos intervienen en los accidentes de esquí alpino y snowboard.

Resultados: Se realizaron 219 encuestas de un total 3911 pacientes atendidos en los distintos puntos de asistencia sanitaria. El mayor porcentaje de encuestados relacionaron su accidente con la distracción o el exceso de confianza, ambos en un 72,2\% de los encuestados. Otros factores que fueron señalados por más del $50 \%$ de los encuestados fueron; la falta de conocimientos

Palabras clave:

Lesiones de esquí. Deportes de nieve. Factores humanos. (un 60,4\% de los encuestados), la falta de seguimiento de las normas (58,5\%), la fatiga $(57,5 \%)$, la falta de conciencia situacional (57\%) y el estrés con $(53,8 \%)$.

Conclusiones: Identificados estos factores humanos más frecuentes durante actividades de esquí alpino y snowboard se podrán realizar acciones para prevenir o contener el error humano. 


\section{Introduction}

Hundreds of millions of people from all over the world practice winter sports ${ }^{1}$. Alpine skiing and snowboarding are considered to have beneficial health effects ${ }^{2}$, although they are also associated with a potential risk of injury. The studies in our geographical areas point to an injury rate of 4.6 per 1000 skiers-day ${ }^{3}$, with differences between alpine skiers ( 2 to 10 injured per 1000 skiers-day) and snowboarders (1 to 6 injured per 1000 snowboards-day) $)^{4,5}$. The high at-risk population which, for example, in Spain was 5,667,845 during the 2018-2019 season ${ }^{6}$, converts these percentages into a high absolute number of injured persons per year. Moreover, the possibility of suffering a serious or fatal injury while skiing or snowboarding means that they are controversially considered to be high-risk sports?.

There are at least three important factors that could affect the safety of activities in the natural environment ${ }^{8}$, in which the aforementioned winter sports are included. These are: environmental factors, technical factors and human factors (HF). While attention is normally paid to the first two factors (e.g. visibility, ice on the piste, skiing level), HF tend to be overlooked even though studies show that they are the most common cause of accidents, while this risk factor is the easiest to prevent and mitigate ${ }^{9}$.

Little has been written about the role of HR in the natural environment10 and there is no specific definition of HF in this scenario. It has been suggested that their definition should include what they are and what is intended to be achieved with them. This proposed definition could be that the analysis of HF is "the ongoing process to identify those actions and decisions which, during activities in the natural environment, may prevent or contain human error"9.

HF can be divided into three categories: psychophysiological (tiredness, fatigue, etc.); cognitive (situational awareness, decision making, etc.); interpersonal relations (teamwork, leadership, communication). Although more than $300 \mathrm{HF}$ have been described, the main accident-related ones are known as the "Dirty Dozen" and are described in Table $1^{9}$. These twelve factors, originally developed for aviation maintenance, are perfectly transferable to activities in the natural environment ${ }^{11,12}$.

Human error will not be reduced simply by observing the interaction of the HF. However, once we understand and see how the presence

Table 1. Main human factors related to accidents.

\begin{tabular}{ll}
\hline & "The dirty dozen" \\
\hline Overconfidence & Distraction \\
Fatigue & Lack of knowledge \\
Stress & Lack of communication \\
Lack of situational awareness & Lack of teamwork \\
Psychological pressure & Lack of assertiveness \\
Failure to comply with norms & Lack of resources and material \\
\hline
\end{tabular}

of HF allows human errors to appear more frequently, we can then introduce protective recommendations in contexts such as alpine skiing and other accidents in the natural environment ${ }^{13,14}$.

A knowledge of the principal human factors would allow us to reduce the risk in winter sports. The aim of this study is to determine what human factors intervene in alpine skiing and snowboarding accidents and how they do so.

\section{Material and method}

Self-administered cross-sectional explanatory personal questionnaire.

\section{Study design}

The study was conducted through the self-administration of a questionnaire by injured persons above the age of 16 years and who were treated at the medical centres of the ski resorts of Masella y Pas de La Casa-Grau Roig during the season 2017-2018. The study was approved and accepted by the local ethics committees and the managements of the ski resorts involved.

\section{Questionnaire design}

The first part of the questionnaire was non-standardised, including basic demographic data (age and sex) and details of the sport practised at the time of the accident. The second part comprised 12 questions on the circumstances of the accident that the respondent had just suffered. The wording in this second part aimed to get the injured person to assess the different personal circumstances prior to the accident. Each of these 12 questions sought to assess the 12 most common conditions or human factors (HF) respectively, based on current literature and termed the "Dirty dozen" (Table 1).

To ensure that each question clearly identified a different $\mathrm{HF}$, these questions were prepared with the help of volunteers selected by the nominal group technique, including ski and snowboard instructors, ski resort users and patrollers-protective service workers. Once the questionnaire had been designed, a pre-test was conducted on a group of volunteers, also selected by the nominal group technique, representing groups from different social environments and levels of education, to ensure correct understanding of the questionnaire. Experts translated the questionnaire from Spanish into Catalan, English and French.

To collect the information, it was decided to use the quantitative technique with closed-ended questions given that it better met the goal of quantifying the phenomena to be studied. Each question had a score from 1 to 10 , with 1 indicating that it was highly unlikely that the circumstance described was related to the accident, while 10 showed that the respondent considered that it was entirely the cause of the accident. Finally, in the analysis of the study, these quantitative data were converted into qualitative ordinals (Table 2 ) with a view to making sense of the quantitative data obtained and better interpreting the results. 
Table 2. Equivalence of the quantitative data in ordinal qualitative data for the human factor variables

\begin{tabular}{lc}
\hline Ordinal categorical variable & Range \\
\hline Not at all & $(1)$ \\
Slightly & $(2-3)$ \\
Sufficiently & $(4-5)$ \\
Quite a lot & $(6-7)$ \\
Considerably & $(8-9)$ \\
Entirely & $(10)$ \\
\hline
\end{tabular}

\section{Sample size}

Previously considering a non-finite population, a confidence level of $90 \%$ with a variability as adverse as possible, of $50 \%$, a maximum admitted error of $6 \%$ and a potential loss percentage of $5 \%$, we calculated that we would need an adjusted sample size of more than 198 questionnaires.

\section{Study protocol}

Simple random sampling was made, whereby the injured person was selected once he or she had met the inclusion criteria. These criteria were evaluated after the normal triage and consisted in: agreement by the injured person to complete the questionnaire; over 16 years of age; minor injury; experience controlled pain ( $<4$ on the verbal numerical pain rating scale) so that the questionnaire could be completed comfortably without negatively affecting the prognosis. The office worker at the medical centre personally explained to each respondent that he/ she should rate each of the conditions described in the questions with a score from 1 to 10, to indicate how they had contributed to the accident, with 1 being extremely unlikely and 10 most certainly,

Finally, descriptive and inferential statistical techniques were used to process the data obtained, using the SPSS version 16 for Windows statistical package. When seeking associations between variables, the age variable was divided into: young <30 years; senior 30 to 45 years; veterans $>45$ years. The variable for sport practised: ski or snowboard. The qualitative ordinal data on the influence of the human factor: "slightly or not at all"and "sufficiently or more". Pearson's $x^{2}$ test was used to seek relationships between variables, given that the variables were qualitative. The statistical significance cutoff was set at $p<0.10$.

\section{Results}

219 questionnaires were completed from a total of 3,911 patients treated at the different healthcare points. 7 questionnaires were rejected (3\%) as they were incomplete. The mean age of respondents was 29 (IQR 23-44), 59\% were male. $68 \%$ were skiing while the remaining $32 \%$ were snowboarding at the time of the accident. The comparison of the epidemiological data according to the sport practised is attached in Table 3.

84.9\% (180) of respondents indicated that one of the HF studied had moderately contributed (range $\geq 4$ ) to the accident.

The highest percentage of respondents related their accident to distraction or overconfidence, both for $72.2 \%$ of respondents. Other factors indicated by more than $50 \%$ of respondents as having contributed to some extent to the accident were: lack of knowledge $(60.4 \%$ of respondents), failure to abide by the norms (58.5\%), fatigue (57.5\%), lack of situational awareness (57\%) and stress (53.8\%).

The human factors that respondents considered to have entirely contributed to the accident were: overconfidence ( $9 \%$ of respondents) distraction (8.5\%) and lack of knowledge (8\%).

$4.3 \%$ of respondents indicated that the misreading of the signs at the facilities could have moderately contributed to the accident and $13.2 \%$ of respondents indicated that it could have been lack of knowledge the material. More detailed information is provided in Table 4.

The human factors that were significantly related to age $(p<0,10)$ were overconfidence (young 58.3\%, senior 40\%, veterans 36.4\%), failure to abide by the norms (young $42.6 \%$, senior $18.3 \%$, veterans $27.3 \%$ ), and lack of knowledge (young 56.5\%, senior 35\%, veterans 13.6\%).

The human factors that were significantly related to the sport practised by respondents $(p<0,10)$ were overconfidence (skiing 38.2\% compared to snowboarding 70.6\%), failure to abide by the norms (skiing $27.1 \%$, compared to snowboarding 44.1\%), and lack of knowledge (skiing $36.8 \%$ compared to snowboarding 51.5\%) (Figure 1).

\section{Discussion}

This study uses a questionnaire to analyse how the most common human factors contribute to alpine skiing and snowboarding accidents. Although there are studies that analyse HF in different activities in the natural environment ${ }^{9-13}$, to the best of our knowledge this is the first study to analyse HF solely in relation to ski resorts.

Table 3. Comparison of the epidemiological data according to the sport practised.

\begin{tabular}{lcccccccc}
\hline & & Total & & & Men & & Women & Age \\
& N & \% & N & \% & N & Mean (IQR) \\
\hline Ski & 144 & 67.9 & 75 & $60 \%$ & 69 & 79.3 \\
Snowboard & 68 & 32.1 & 50 & $40 \%$ & 18 & 20.7 & $25(21-30)$ \\
Total & 212 & $100 \%$ & 125 & $100 \%$ & 87 & $100 \%$ \\
\hline
\end{tabular}


Table 4. Percentages for the contribution of the different human factors to the accident according to the respondents.

\begin{tabular}{|c|c|c|c|c|c|c|}
\hline & Not at all & Slightly & Sufficiently & Quite a lot & Considerably & Entirely \\
\hline Overconfidence & $27.8 \%$ & $23.6 \%$ & $15.6 \%$ & $17.9 \%$ & $6.1 \%$ & $9.0 \%$ \\
\hline Fatigue & $42.5 \%$ & $34.0 \%$ & $12.3 \%$ & $8.0 \%$ & $2.8 \%$ & $0.5 \%$ \\
\hline Stress & $46.2 \%$ & $38.2 \%$ & $5.7 \%$ & $6.1 \%$ & $2.4 \%$ & $1.4 \%$ \\
\hline Lack of awareness & $42.5 \%$ & $27.8 \%$ & $11.8 \%$ & $9.0 \%$ & $4.2 \%$ & $4.7 \%$ \\
\hline Psychological pressure & $63.7 \%$ & $29.2 \%$ & $2.4 \%$ & $2.4 \%$ & $1.9 \%$ & $0.5 \%$ \\
\hline Failure to abide by norms & $41.5 \%$ & $25.9 \%$ & $12.3 \%$ & $6.6 \%$ & $8.5 \%$ & $5.2 \%$ \\
\hline Distraction & $27.8 \%$ & $22.2 \%$ & $14.6 \%$ & $17.9 \%$ & $9.0 \%$ & $8.5 \%$ \\
\hline Lack of knowledge & $39.6 \%$ & $18.9 \%$ & $17.5 \%$ & $8.0 \%$ & $8.0 \%$ & $8.0 \%$ \\
\hline Incorrect reading of the signage at the facilities & $66.0 \%$ & $29.7 \%$ & $0.9 \%$ & $1.4 \%$ & $0.9 \%$ & $0.9 \%$ \\
\hline Lack of teamwork (disregard colleagues) & $65.1 \%$ & $29.7 \%$ & $2.4 \%$ & $1.4 \%$ & $0.5 \%$ & $0.9 \%$ \\
\hline Lack of adaptation to difficulty (assertiveness) & $58.0 \%$ & $33.0 \%$ & $4.2 \%$ & $2.8 \%$ & $0.9 \%$ & $0.9 \%$ \\
\hline Lack of resources & $60.4 \%$ & $26.4 \%$ & $5.7 \%$ & $3.8 \%$ & $1.4 \%$ & $2.4 \%$ \\
\hline
\end{tabular}

Figure 1. Comparison of percentages according to the activity in which the respondents considered that the different HF had sufficiently contributed to the accident.

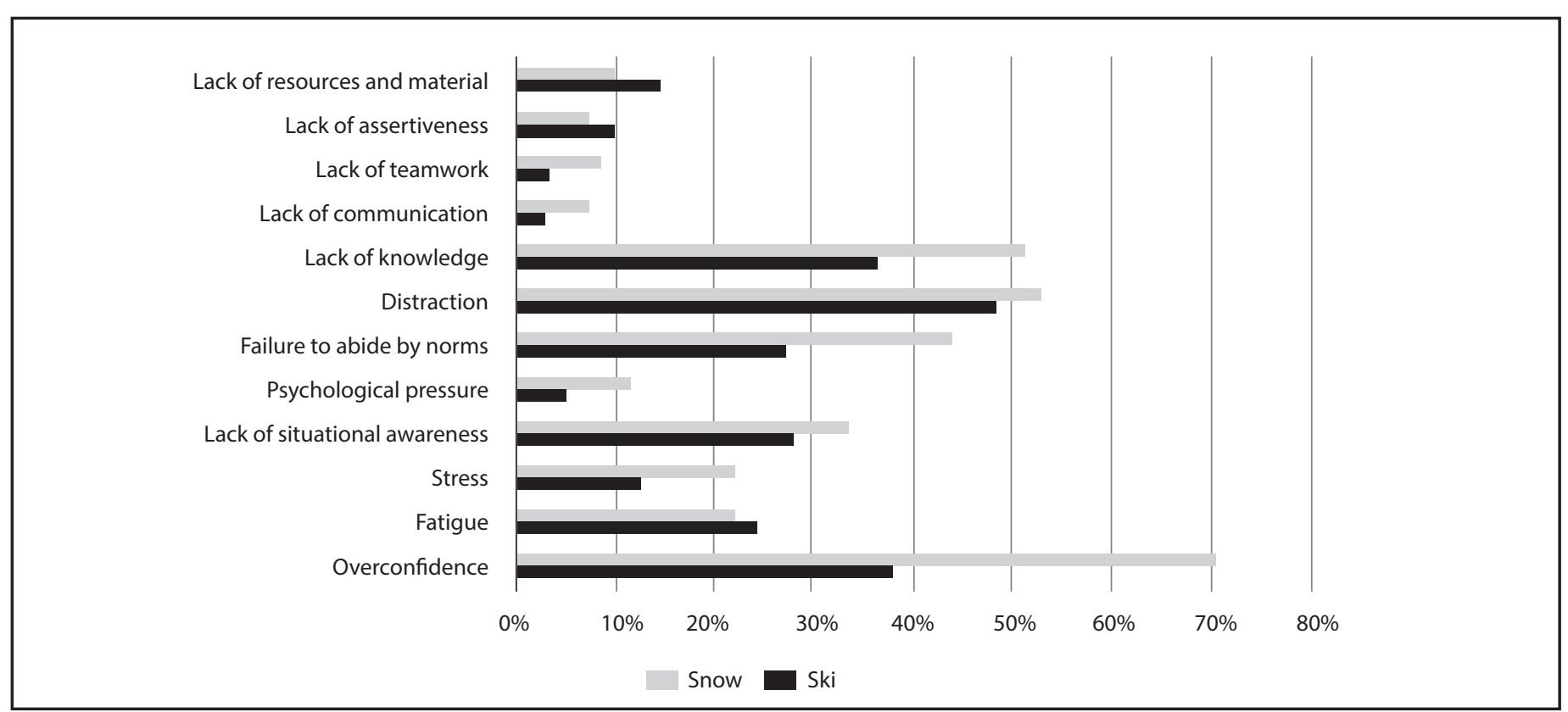

\section{Importance of the human factor in ski resort accidents}

A study on the psychological aspects of mountain accidents confirmed that, in the case of alpine skiing, among the direct causes of accidents put forward by survivors were HF such as: skiing technique errors, over-fatigue and excessive speed. The contributing factors included: overconfidence, low technical level, poor concentration, as well as a combination of: favourable weather conditions, perception of little difficulty, recklessness and optimal piste conditions. The authors concluded that there are a combination of factors that lead to multiple mistakes ${ }^{13}$. This study, together with others, highlights the fact that the weighting of each of the human factors is complicated, although their importance in accidents is evident ${ }^{13,15}$.

The results of the study indicate that $84.9 \%$ of respondents consider that at least one of the $12 \mathrm{HF}$ analysed "sufficiently" contributed to the accident. Such a high percentage suggests that the human factor plays a key role in the cause of skiing and snowboarding accidents, even perhaps above the other environmental factors and material factors. The accident rate studies of other sports in the natural environment that have investigated the influence of HF, also point to this factor as an important cause of accidents. This is the case of BASE jumping, with 
similar percentages (86\%) to our study ${ }^{16}$. These results are also repeated in other studies such as those analysing air sports accidents (paragliding, hang gliding, etc.) where the influence of HF appears to be constantly between 55 to $85 \%^{17-19}$.

\section{Distraction and overconfidence, human factors most related to ski resort accidents}

According to the respondents, the HF that most contributed to the accident were: distraction and overconfidence. These same HF are highlighted in the annual studies of the Swiss Bureau de Preventions des Accidents, where more than 76,000 alpine skiing accidents are analysed each year ${ }^{20}$.

The study Contributors to human error and how to lower rates of committing error establishes that the three main contributors to human error are ineffective supervision, overconfidence and an environment that favours distractions, where factors such as fatigue and complacency are also considered ${ }^{21}$.

With regard to road safety, a lack of attention while driving is recognised as one of the main contributing factors to road accidents, contributing to $80 \%$ of crashes and $65 \%$ of near-miss crashes ${ }^{22}$. Chamorro, in his study on the psychological aspects of mountain accidents, emphasises that $18.39 \%$ are caused by distraction, according to the injured persons interviewed ${ }^{13}$. In the context of Ski resorts, Sévigny in their work on "Les accidents en ski alpin dans la région des Laurentides", observed that distraction was associated with the accident, in $27 \%$ of cases they found that distraction disappeared as a cause of accidents when these occurred on the most difficult pistes, and no association between fatigue and distraction appears to exist ${ }^{23}$.

Distraction is anything that takes our minds off a task when we need to attend to something specific, even if only for a very brief moment in time (e.g. when rearranging or adjusting material, eating or talking on the phone while moving). Given that our minds work faster than our hands, a distraction can very quickly steer us away from the task at hand. A distraction could involve a failure to complete all the necessary steps or to follow the established procedure (e.g. a correct ski turn). And if something has distracted us, once we resume the activity, we will not carry on where we left off (e.g. starting the execution of a turn too late). When the lack of attention is caused by internal factors such as thoughts and reflections, this is termed cognitive distraction or inattention. This could, for example, cause us to make less effort to check for other skiers at piste intersections or to reduce our peripheral vision that would have helped us to avoid possible collisions, etc.) Given that there is no clear conceptual delimitation between distraction and inattention ${ }^{24}$, these concepts have been grouped together under the same HF: "distraction". It is easy to understand that we recognise, more or less explicitly, that distraction affects safety and puts it at risk when alpine skiing or snowboarding.

In general, individuals tend to underestimate the potential risk of distractions and, in turn, to overestimate their ability to do several things at the same time ${ }^{25}$. With regard to road safety, in order to reduce this error, the reinforcement of education and training, and awareness-raising campaigns are recommended ${ }^{26}$. Checklists ("everything ready before starting the descent...") are also good tools for combating these errors. In short, there is a need to be proactive in environments in which distractions are possible and focus on the task in hand, avoiding any other task. Studies demonstrate that effective task management can reduce the risk of human error by $81 \%{ }^{27}$.

Complacency or overconfidence, an insidious cause of error that generally occurs when a people perform a task repetitively and rely on pattern recognition. This causes us to take our minds off potentially dangerous situations and leads us to think that certain risk situations are not so, apparently because we are full of "false positives". Everything went fine before, so nothing bad is going to happen now... It is easy to become complacent when using the same terrain and routes, a characteristic situation when skiing and snowboarding at ski resorts. In our study, $72 \%$ of respondents related their accident with overconfidence. As Chamorro indicated in his study ${ }^{13}$, when skiing at ski resorts, overconfidence is a more important factor than when skiing off-piste, according to the responses of the injured skiers interviewed.

Some studies indicate that, in certain sports, confidence has a protective effect, reducing the perception of risk ${ }^{27,28}$. But, at what point does this confidence shift from a protective to a negative effect? In the context of accidents at work, it occurs when complacency makes you feel that the task can be done with your eyes closed and it becomes second nature ${ }^{29}$. At the ski resort, this behaviour could lead you to increase your speed, not to value the condition of the snow, tunnel vision, be less vigilant.

This human factor can be mitigated by analysing each situation at all times and in its context (e.g. What are the piste conditions like at the moment?) Likewise, a "double safety check" could be essential.

\section{Distraction, overconfidence and lack of knowledge: human factors that are the direct cause of ski resort accidents}

Although distraction and overconfidence were not the only HF that were most frequently identified, together with a lack of knowledge, they stood out due to the fact that they were considered to have entirely contributed to the accident, thereby recognising these factors as a direct cause of accidents.

Lack of knowledge is a HF that is more prevalent in activities in which there is a high presence of automatic skills ${ }^{25}$ such as alpine skiing and snowboarding, all the more so if these are practised in a ski resort environment. We must be aware of our limitations and be humble and not overestimate our skills, thereby avoiding falling prey to the Dunning-Kruger effect (cognitive bias by which people with low ability or knowledge overestimate their ability) $)^{30}$. Particularly when faced with a situation that we are not sure how to resolve". Education and training are the best safety tools for addressing this human factor, although as the study shows, it is not sufficient to have good knowledge. 


\section{Failure to comply with norms, fatigue, lack of situational awareness and stress, are contributing factors to accidents in ski resorts}

Norms are those unwritten rules that are followed or tolerated by the majority of athletes. However, on occasions, there are persons who establish their own rules or criteria, and which are not always the most appropriate for the established safety. It is customary to hear the oft-repeated excuse that something "has always been done that way". This human factor can be mitigated by ensuring that everyone follows the same standards and takes nothing for granted. Ski resorts are governed by the Norms of Conduct of the International Ski Federation (ISF) for skiers and snowboarders ${ }^{31}$.

The questionnaire identified with examples the failure to follow the norms, such as speeding or not wearing a helmet among others. This human factor constantly appears as a contributing factor in other accident studies, both with regard to road safety ${ }^{32}$, sports activities ${ }^{13}$, and ski resorts ${ }^{28}$. Excessive speed has been identified as a double contributing factor, given that speed is related to greater probability of being involved in an accident, but it also affects the severity of the accident suffered $^{33}$. Excessive speed is also associated with other factors such as risk behaviour ${ }^{2}$, overconfidence ${ }^{27}$ and pressure of the environment ${ }^{13}$.

Another example of a failure to follow the norms is to reject the use of a helmet. Although it has been hypothesized that the use of a helmet at ski resorts could be associated with greater risk behaviour ${ }^{34}$ and increased injury to other parts of the body ${ }^{35}$, a number of studies have demonstrated that this is not the case $\mathrm{e}^{36,37}$. The use of helmets has increased over the last 20 years, and in the Alps $90 \%$ of adults and $100 \%$ children now wear helmets ${ }^{37}$. As has been demonstrated, compliance with this norm implicitly leads to fewer minor and major head injuries ${ }^{38}$.

$57.5 \%$ of the injured persons interviewed indicated that fatigue had contributed to the accident. Fatigue is a feeling of tiredness, reduced energy, and increased effort to perform tasks effectively and without errors. We would be facing a degradation of the human body-system, caused by prolonged, strenuous work that requires particular effort. This leads to a fall in concentration and the awareness level. It is estimated that fatigue contributes to $20-30 \%$ of traffic accidents (air, road, rail) ${ }^{39}$. In the context of sports accidents, this human factor has also been mentioned by injured persons in other studies, such as climbing, mountaineering, mountain skiing and alpine skiing. Alterations in dehydration biomarkers have been associated with fatigue, poor performance and a risk of injury ${ }^{40}$. With regard to alpine skiing, fatigue has been described as a direct cause of accidents ${ }^{13}$.

This human factor can be mitigated with adequate rest, healthy eating and correct hydration. There is a need to be alert for the symptoms characteristic of fatigue, with regard to oneself and to colleagues alike. In the event of fatigue, tasks that are physically and psychologically demanding should be avoided ${ }^{15}$.

More than half the injured persons interviewed indicated that the lack of situational awareness had contributed to the accident. This HF occurs when there is a lack of alertness and vigilance. In particular, when a task of activity is habitually performed, then a person tends to develop a lack of situational awareness ${ }^{14}$. There is an unconscious competence that makes us act on auto-pilot. This automaticity is a mechanism developed with experience and which can affect the awareness of the situation and provide good performance with a very low level of attention. When practising a demanding physical task such as alpine skiing or snowboarding, automaticity may positively affect situational awareness by reducing the demands for limited attentional resources ${ }^{14}$. However, on the other hand, the awareness of the situation may be negatively affected by the automaticity of the cognitive processes due to a reduction in the response capacity to new stimuli (e.g. skiing over uneven terrain). This human factor is closely related to complacency. The lack of communication, assertiveness and knowledge, as well as stress and fatigue all significantly contribute to the lack of situational awareness. The strategies to mitigate the lack of situational awareness are based on correct safety culture, checks and inspections. For example, at a ski resort, while going up in the chair lift, we should be deciding which pistes are the least crowded, which are affected by the sun and any noise by made skiers as they slide on their ski edges, indicating that the snow is frozen.

Stress is the final human factor indicated by the respondents as contributing to accidents. Stress is the subconscious response to extremely demanding situations, causing psychosomatic reactions or psychological disorders. This does not only relate to the working environment, but also to our personal lives ${ }^{15}$. Stress can lead to errors when it is excessive as it acts as a distraction and reduces concentration levels when performing complex tasks such as a day skiing. The relationship between the stress response and the greater incidence of injuries and accidents in the sports context has been extensively discussed by different authors ${ }^{41,42}$, establishing the existence of physiological causes (over-working of different systems of the body), behavioural causes (relaxation in preventive measures) and psychological causes (inadequate attentional focus $)^{43}$. This human factor is mitigated by maintaining awareness of it, with a suitable warm-up and inspection of one's personal equipment. If we feel stressed, it is important to take short breaks, encourage good communication with colleagues and avoid the idea of non-stop skiing (or without a break) to make the most of the price of the ski pass or of your only free day, particularly for those who do not ski on a regular basis. The same actions that helped to mitigate fatigue: healthy eating and correct hydration, doing moderate physical exercise, keeping regular sleep and rest patterns, will all help to reduce stress levels ${ }^{15}$.

\section{Conclusions}

As shown by our results and those of other earlier studies ${ }^{13}$, there are certain human factors that can be identified in alpine ski and snowboard accidents. Distraction and overconfidence are the human factors most related to ski resort accidents, according to the victims. These HF, 
together with other contributing factors discussed herein, must be the target of possible preventive actions. In this way, not only will attention be paid to environmental and technical aspects, but also to those actions and decisions which, during activities in the natural environment, can prevent or contain human error. To facilitate these preventive actions and decision making, which may be difficult to make on an ongoing basis (for example during a complete skiing day at a winter ski resort) it has been demonstrated that it could be effective to be aware of, and to abide by some basic norms of conduct ${ }^{44}$. This type of training, based on decision making and following basic prevention norms, is already being used by other institutions such as the Safety Committee of FEDME (Spanish Federation of Mountain and Climbing Sports) ${ }^{45}$, with great acceptance. At the ski resorts, this type of information, used during learning and in prevention campaigns, based on basic concepts and focused on those HF that have proven to be the greatest contributors, would be extremely useful for the prevention of accidents.

\section{Limitations}

One of the limitations of this study is the understanding of some of the concepts included in the questionnaire. Although we did try to minimise this through the pre-test during the questionnaire design and with the explanations by the office workers. Another limitation is the possible bias produced by the self-selection of the subjects prepared to respond to the questionnaire. Furthermore, we do not have the figure for the questionnaires rejected by injured persons.

A further limitation is whether or not amateurs are able to reliably identify the causes attributable to their accident, given that they are not aware of (or cannot identify) many of the risk factors involved. Certainly, they can make an approximation through a directed survey, as in this study.

\section{Acknowledgements}

We would like to thank Montse Casals, Rocío Ramos, Griselda Ramos and Roxana Bustos, for all their help. As well as the ski resorts of Masella, Pas de la Casa and Grau Roig for their collaboration.

\section{Conflict of interests}

The authors have no conflict of interest at all.

\section{Bibliography}

1. Niedermeier M, Ruedl G, Burtscher M, Kopp M. Injury-Related Behavioral Variables in Alpine Skiers, Snowboarders, and Ski Tourers-A Matched and Enlarged Re-Analysis. Int J. Environ Res Public Health. 2019;16:3807

2. Burtscher M, Federolf PA, NachbauerW, Kopp M. Potential health benefits from downhill skiing. Front Physiol. 2019;9:1924.

3. Subirats E, Soteras I, Subirats G, Perarnau S, Riu F, Caralt X. Differences in the pattern of injuries between snowboarding and alpine skiing: an analysis of 9,147 casualties during five seasons. Archivos de Medicina del Deporte. 2011;142:86-92.

4. Rønning R, Gerner T, Engebretsen L. Risk of injury during alpine and telemark skiing and snowboarding. The equipment-specific distance-correlated injury index. Am J Sports Med. 2000;28:506-8.
5. Warme WJ, Feagin JA, King P, Lambert KL, Cunningham RR. Ski injury statistics, 1982 to 1993. Jackson Hole Ski Resort. Am J Sports Med. 1995;23:597-600.

6. El esquiador en España. Informe anual del sector del esquí. ATUDEM. 2019.

7. Castanier C, Le Scan C, Woodman T. Who takes risks in high-risk sports? A typological personality approach. Res Q Exerc Sport. 2010;81:478-84.

8. Fuster J, Elizalde B. Riesgo y actividades físicas en el medio natural. Un enfoque multidimensional. Apunts: Educación física y deportes. 1995;41:94-107.

9. De Decker R, Tölken G, Roos J. Human factors: Predictors of avoidable wilderness accidents? SAMJ S Afr Med J. 2017;107:669-73.

10. Salmon PS, Williamson A, Mitsopoulos-Rubens E, Rudin-Brown Ch, Lenné M. The role of human factors in led outdoor activity incidents: literature review and exploratory analysis. Monash University. 2009

11. Amat J. Seguridad en montaña. Los peligros ocultos. Madrid. Ediciones Desnivel; 2017 p.16.

12. Taibo M. Prevención de riesgos para colectivos en montaña. Asturias. Ediciones Cordillera Cantábrica; 2017.

13. Chamorro Lusar A. Fernández-Castro J. The perception of causes of accidents in mountain sports: A study based on the experiences of victims. Accident Analysis and Prevention. 2009;41:197-201.

14. The Human Factors. Dirty Dozen. 2020.

15. Ayora A. Gestión del riesgo en montaña y actividades al aire libre. Madrid. Ediciones Desnivel; 2011. p. 115.

16. Hart CL, Griffith JD. Human error: The principal cause of skydiving fatalities. J Hum Perform Extrem Environ. 2003;7:7-9.

17. Bouchat P, Brymer E. BASE Jumping Fatalities Between 2007 and 2017: Main Causes of Fatal Events and Recommendations for Safety. WMJ. 2019;30:407-11

18. Margreiter R, Lugger LJ. Hang-gliding accidents. British Medical Journal. 1978;1:400-2.

19. Schulze W, Hesse B, Blatter G, Schmidtler B, Muhr G. Pattern of injuries and prophylaxis in paragliding. Sportverletz Sportschaden. 2000;14:41-9.

20. Communiqué de presse. Bureau de Preventions des Accidents Suisse. 2020.

21. Latino JR. Contributors to human error and how to lower rates of committing error Briefings on Patient Safety. 2008;9(2):8-9.

22. Dingus TA, Klauer SG, Neale VL, Petersen A, Lee, SE, Sudweeks J, Perez MA. The 100-Car Naturalistic Driving Study. Technical Report No. Washington DC. National Highway Traffic Safety Administration; 2006

23. Sévigny D. Les accidents en ski alpin dans la région des Laurentides. Montreal. Départament de Santé Communaitaire de l'Hotel Dieu de Saint Jérône; 1990.

24. Montes SA, Ledesma RD, Poó FM. Estudio y prevención de la distracción e inatención en la conducción. Avances en Psicología Latinoamericana. 2014;32:115-29.

25. RanneyTA. Driver distraction: A review of the current state-of-knowledge. Report DOT HS 810-704, National Highway Traf c Safety Administration, Washington D.C. United States. 2008

26. Latino JR. The effects of distractions on human performance. Briefings on Patient Safety. 2008;9:10-1.

27. Chamarro A, Rovira T, Edo S, Fernandez-Castro J. Risk Judgments in Climbers: The Role of Difficulty, Meteorological Conditions, Confidence and Appropriate Tools. Leisure Sciences. 2008;41:221-35

28. Chamarro A. Factor humano: Cómo se valora el riesgo y sus implicaciones. Neu i Allaus. 2014;6;23-4

29. Latino JR. Distractive environments: Mitigating complacency. Briefings on Patient Safety. 2008;9:10-11.

30. Kruger J, Dunning D. Unskilled and Unaware ofi t: How difficulties in Recognizing One's Own Incompetence Lead to Inflated Self-Assessments. Journal of Personality and Socia Psychology. 1999;77:1121-34.

31. $10 \mathrm{FIS}$ rules for conduct. FIS environmental rules. Approved by the FIS Congress 2002 2016.

32. Informe mundial sobre prevención de los traumatismos causados por el transito Washington DC. Organización Mundial de la Salud. OPS; 2004.

33. Montoro L, Roca J, Lucas-Alba A. Creencias de los conductores españoles sobre la velocidad. Psicothema. 2010;22(4):858-64.

34. Scott MD, Buller D B, Andersen PA, Walkosz BJ, Voeks JH, Dignan MB, Cutter GR. Testing the risk compensation hypothesis for safety helmets in al pine skiing and snowboarding. InjPrev. 2007:13:173-7.

35. Hagel BE, Pless IB, Goulet C, Platt R, Robitaille Y.The efect of helmet use on injury severity and crash circumstances in skiers and snowboarders. Accid Anal Prev. 2005:37:103-8. 
36. Ruedl G, Burtscher M, Wolf M, Ledochowski L, Bauer R, Benedetto K, Kopp M. Are selfreported risk-taking behaviour and helmet use associated with injury causes among skiers and snowboarders?. Scand J Med Sci Sports. 2015;25:125-30.

37. Ruedl G, Posch M, Niedermeier M, Greier K, Faulhaber M, Schranz A, Burtscher M. Are risk-taking and ski helmet use associated with an $A C L$ injury in recreational alpine skiing?. Int J Environ Res Public Health. 2019;16:3107.

38. Haider AH, Saleem T, Bilaniuk JW, Barraco RD. An evidence-based review: efficacy of safety helmets in the reduction of head injuries in recreational skiers and snowboarders. J Trauma Acute Care Surg. 2012;73:1340-7.

39. Akerstedt T, Mollard R, Samel A, Simons M, Spencer M. Role of EU FTL legislation in reducing cumulative fatigue in civil aviation. European Transport Safety Council. 2003.

40. Lee EC, Fragala MS, Kavouras SA, Queen RM, Pryor JL, Casa DJ. Biomarkers in Sports and Exercise:Tracking Health, Performance, and Recovery in Athletes. J Strength Cond Res. 2017;31:2920-37.
41. Sandín B. El estrés. En: Belloch A, Sandín B, Ramos F.Manual de Psicopatología. Madrid. Editorial McGraw-Hill; 1995.

42. Crespo M, Labrador FJ. Evaluación y tratamiento del estrés. En: Buceta JM. Intervención Psicológica y Salud: Control del Estrés y Conductas de Riesgo. Madrid. Editorial Dykinson; 2001.

43. Díaz, P, Buceta JM, Bueno AM. Situaciones estresantes y vulnerabilidad a las lesiones deportivas: un estudio con deportistas de equipo. Revista de Psicología del Deporte. 2004;14:7-24

44. Brannon L, Feist J. Health Psychology: An Introduction to Behavior and Health. Belmont. Wadsworth/Thomson Learning; 2000 .

45. Tríptico código de seguridad FEDME. (consultado 2204/2020). Disponible en: https:// seguridadfedme.es/triptico-interior-codigo-seguridad-fedme. 